\title{
Third mission: a challenge for scholars? An editorial
}

\author{
Thomas W. Guenther ${ }^{1}$ (D)
}

C Springer-Verlag GmbH Germany, part of Springer Nature 2019

\begin{abstract}
"What is the impact of your research?" "Oh, well, good question. I guess the impact factor of the journal I last published in was about 2.5."
\end{abstract}

This is the core of a recent conversation with a reputational scholar at a cocktail reception of an international conference. The conversation captures one of the present challenges for research. Administrators, donors and the general public want science to have impact on economy and society. Besides teaching and research a contribution to the so-called "third mission" is requested as one of the outcomes of higher education institutions.

Taking some minutes, leaning back and considering what we do day by day and what we are intended to do, might help letting the ivory tower behind us and getting new insights about our business. Following UNESCO and the Guinness Book of Records, the University Al-Qarawiyyin in Fes (Maroc) is the oldest, still existing university, founded in 859 as a place of learning. However, universities are not given per se and are not granted forever. What is our purpose? What are we for? Typically, scholars regard research as the primary objective of our engagement. Teaching as the original purpose of the first universities results in ambiguous feelings. One group considers teaching students still as the essence of a higher education institution. A second group follows the Humboldtian education ideal of a holistic combination of research and teaching, which came popular in the nineteenth century. However, I also see a third group, which regards teaching as a burden or as a compromise, a scholar has to take if she/he wants to do research.

Why do we need a third mission? The third mission is our contribution to society besides research and teaching. Firms are nowadays requested to follow the triple bottom line which means that besides economic and ecological sustainability firms are accounted for their social contribution to the society. This is also true in a similar manner for private universities, whose business is teaching and research. However, this is even more important for public universities financed significantly by the tax-payer. Financial grants from the state can only be justified in contrast to private higher education institutions when we are able to create in

Thomas W. Guenther

thomas.guenther@tu-dresden.de

1 Technische Universität Dresden, Dresden, Germany 
return additional welfare for the society. A state with public universities should be in the long-term better off than a state where higher education is only private. Otherwise, universities could be private only.

What is this third mission? Going back to the early foundations of universities in Arabic countries, a good general level of education and expertise is one part of this third mission, which allows graduated students to better perform their professions and to better contribute to the society. Another third mission is the creation of knowledge. We are living in a knowledge society which is defined by the fact that knowledge has become the most important production factor leaving the industrial society with material production factors behind us. Knowledge is about generating truth, about better understanding, about technologies and methods, and about facts. However, the knowledge society is nowadays challenged by a post-factual society and by post-truth politics which questions how we do research and how we transfer knowledge today. Do we have the right skills to communicate our knowledge to the general society outside the ivory tower? Do non-scholars or scholars in other fields understand what we found and capture the knowledge we created?

Another component of the third mission is more and more requested: direct impact on economy and on society. Universities around the world started to measure these kinds of impacts of their activities in research and teaching. Donors and administration want to make higher education institutions accountable for this direct contribution to the third mission. Measures are suggested and implemented such as the number of talks to non-university members, number of spin-offs, number of round-tables with practitioners in your field, the amount of third party funds from firms and private institutions etc. All in all, reliable and valid metrics are difficult to find and difficult to implement. After decades of focus on research, especially younger scholars feel surprised because they learnt everything how to do excellent research, but not so much about how to approach practice and how to communicate with the society. Nevertheless, when looking on the purpose of higher education we have to realize that we have to contribute somehow to society to justify research and teaching and to finally justify our funding. Luckily, there are many opportunities how to contribute to economy and to society and thus to fulfill our third mission if the existing opportunities are not externally limited to some paths only.

The three papers in this issue may contribute to the first component of a third mission. We hope that the papers expand our knowledge and, thus, may inform practitioners how to better use and design management accounting and management control systems.

Ewelina Zarzycka, Justyna Dobroszek, Lauri Lepistö and Sinikka Moilanen analyze based on a case study the use of a management control system in the context of a business process outsourcing company, which faces the simultaneous need for process and management innovation and standardization. The authors describe the process of taking over business processes from Western European firms by Eastern European outsourcing specialist, whose job is to innovate and to standardize the processes to finally hand them over again to less expensive Asian outsourcing firms. The study examines the relationships between different levers of control and their 
nature to explain how levers of control can create consistent and countervailing reinforcement that supports the co-existence of innovation and standardization.

Tabea Franziska Hirth-Goebel and Barbara Weißenberger address an issue which is also of overwhelming practical relevance, the ethical behavior of employees, especially of management accountants, in organizations. Based on survey data from 90 international management accountants, the authors find evidence that the ethical environment strongly affects management accountants' tendency not to engage in ethically questionable behavior. In detail, the results support the notion that the connection between ethical awareness and the intention to engage in ethically questionable behavior is indirect and mediated by the level of ethical experience, i.e. the individuals' exposure to ethical role models in organizations.

Also the third paper of Pasi Aaltola is very much informed by practice and may inform the strategic thinking of managers from an accounting perspective. Using interview data from managers working with strategic roles in various organizations, an understanding of the experienced potentials and pitfalls of accounting in strategic thinking is offered. The authors use their results to elaborate a framework addressing the dual nature of accounting in strategic contexts.

We hope that the scholarly readers of the Journal of Management Control can prosper from papers of this issue, but we also hope that we can contribute to expand the knowledge for our society on how to deal with issues of management accounting and control, and, thus contribute a little bit to the third mission.

Dresden, October 2019

For the team of editors

Thomas W. Guenther

Managing editor

Publisher's Note Springer Nature remains neutral with regard to jurisdictional claims in published maps and institutional affiliations. 